\title{
Positive Surgical Margins (PSM) after Open Retropubic Radical Prostatectomy: Evaluation of Patient Survival
}

\author{
Babacar Sine ${ }^{1 *}$, Abdoulaye Ndiath ${ }^{1}$, Ndéye Aissatou Bagayogo ${ }^{2}$, Alioune Sarr ${ }^{1}$, Amath Thiam ${ }^{2}$, \\ Cyrille Ze Ondo1, Ousmane Sow ${ }^{1}$, El Hadji Malick Diaw1, Moussa Séne1, Babou Sakho1, \\ Cheikh Bécaye Gassama1, Ibrahima Ngom¹, Yaya Sow ${ }^{1}$, Babacar Diao¹, Alain Khassim Ndoye1 \\ ${ }^{1}$ Urology Andrology Department of Aristide Le Dantec Hospital, Dakar, Sénégal \\ ${ }^{2}$ Urology Andrology Department of Ouakam Military Hospital, Dakar, Sénégal \\ Email: *papesine@yahoo.fr
}

How to cite this paper: Sine, B., Ndiath, A., Bagayogo, N.A., Sarr, A., Thiam, A., Ze Ondo, C., Sow, O., Diaw, E.H.M., Séne, M., Sakho, B., Gassama, C.B., Ngom, I., Sow, Y., Diao, B. and Ndoye, A.K. (2021) Positive Surgical Margins (PSM) after Open Retropubic Radical Prostatectomy: Evaluation of Patient Survival. Open Journal of Urology, 11, 282-288.

https://doi.org/10.4236/oju.2021.117026

Received: June 2, 2021

Accepted: July 23, 2021

Published: July 26, 2021

Copyright (อ 2021 by author(s) and Scientific Research Publishing Inc. This work is licensed under the Creative Commons Attribution International License (CC BY 4.0).

http://creativecommons.org/licenses/by/4.0/ (c) (i) Open Access

\begin{abstract}
Background: Many patients who have had radical prostatectomy for prostate cancer may present with microscopic extraprostatic extension of the disease. Positive surgical margins are a common pathological finding in this subgroup of patients. To report the epidemiological, clinical and therapeutic aspects of PSM after radical prostatectomy (RP) and to evaluate the follow-up of patients. Patients and methods: A single-center retrospective descriptive study of patients who underwent radical prostatectomy between June 1, 2004 and December 31, 2019 was conducted. Patients who had radical prostatectomy with PSM on pathology report were included. The parameters studied were age, initial prostate specific antigen (PSA), Gleason and International Society of Uropathology (ISUP) scores, cTNM and pTNM stages, operative technique, PSA levels after surgery, adjuvant treatment and patient survival. Results: Eighty-six (86) radical prostatectomies were performed. PSM was found in 23 patients (26.7\%). The mean age of the patients was $63.7 \pm 6.1$ years. The mean preoperative total PSA was $31.5 \mathrm{ng} / \mathrm{mL}$ (6.31 - $146 \mathrm{ng} / \mathrm{mL})$. Prostate biopsy showed only prostatic adenocarcinoma. Thoracic-abdominopelvic CT was performed in all patients. Prostate cancers were found at the localized stage in 12 patients and locally advanced in 11 patients. A classification adjustment was obtained after pathological examination of the surgical specimen. The ISUP score 3 and 1 on the surgical specimen were in the majority with 9 and 7 patients respectively. After the recurrence, all patients who consented received hormone therapy, which was either medical with Goserelin and Triptorelin (7 patients) or surgical with testicular pulpectomy (1 patient). PSA was undetectable $(<0.1 \mathrm{mg} / \mathrm{mL})$ in 4 patients. The mean overall survival
\end{abstract}


(OS) time was 28.1 months. Biological recurrence-free survival in the series was 25.7 months. Conclusion: RP with PSM is a fairly common condition that varies from less than $10 \%$ to more than $40 \%$ depending on the stage of the disease and the operators, and for which the main mean of treatment in our practice setting is hormone therapy.

\section{Keywords}

Prostate Cancer, Surgical Margins, Survival

\section{Introduction}

Prostate cancer is leading cancer in older men and the second leading cause of death (after lung cancer). It is the fourth leading cause of death due to cancer in the general population [1]. In Africa, prostate cancer is diagnosed primarily at locally advanced or metastatic stage [2]. In Senegal, most prostate cancers are diagnosed in locally advanced or metastatic stage [3]. Radical prostatectomy (RP) is a surgical treatment of prostate cancer in which the prostate and seminal vesicles are removed [4]. The oncological principles of cancer surgery advocate the complete removal of cancer with negative surgical margins. In localized prostate cancer, the management of the positive surgical margin (PSM) after radical prostatectomy remains controversial [5] [6]. Positive margins after total prostatectomy are a common pathological situation $(10 \%-40 \%)$ in the daily practice of urologists dealing with prostate cancer. The presence of positive margins correlates with the presence of residual tumor in about $50 \%$ of cases [7]. A positive surgical margin (PSM) is defined as the presence of cancerous tissue in contact with the inked borders of the prostatectomy specimen [8]. In our regions, there is no study interested in PSM. The aim of this study was to report the epidemiological, clinical and therapeutic aspects of PSM after radical prostatectomy and to evaluate the follow-up of patients.

\section{Patients and Methods}

This was a single-center retrospective descriptive study of patients who underwent radical prostatectomy (RP) between 1 June 2004 and 31 December 2019 in Urology-Andrology department of Aristide Le Dantec Hospital in Dakar, Senegal. We collected data from the medical records and registers of patients. All patients who had (RP) with invaded surgical margins on pathology report were included. A positive surgical margin (PSM) was defined as the presence of cancerous tissue in contact with the inked borders of the prostatectomy specimen. Patients who had RP with margins status not specified on the pathology report, patients who had invaded margins and were lost to follow-up, and patients with unexploitable records were not included. The parameters studied were age, initial PSA, Gleason and ISUP scores, cTNM and pTNM stages, operative technique, PSA levels after prostatectomy, adjuvant therapy and patient survival. 
Excel 2013 software was used for statistical analysis and survival was calculated according to Kaplan Meier.

\section{Results}

During the study period 86 radical prostatectomies were performed. PSM was found in 23 patients (26.7\%). The mean age of the patients was $63.7 \pm 6.1$ years (54 - 74 years). The mean preoperative total PSA level was 31.5 (6.31 - 146 $\mathrm{ng} / \mathrm{mL}$ ). The prostate biopsy showed only prostatic adenocarcinoma. The ISUP 1 group was predominant in our series with 15 patients. Magnetic Resonance Imaging (MRI), Thoracic-abdominal-pelvic Computer Tomography (CT) and scintigraphy was performed to assess the extension of the disease. The prostate cancers were found at the localized stage in 12 patients and locally advanced in 11 patients. A classification adjustment was obtained after pathological examination of the surgical specimen. T-stage was underestimated in 12 patients. All patients who had cancers classified as intermediate risk of recurrence according to D’Amico's classification were finally at high risk of recurrence (Table 1).

Table 1. Classification of cancers (TNM and ISUP).

\begin{tabular}{|c|c|c|c|c|c|c|}
\hline Age & $\begin{array}{l}\text { PSA Initial } \\
(\mathrm{ng} / \mathrm{mL})\end{array}$ & CTNM & $\begin{array}{l}\text { ISUP Pré } \\
\text { opératoire }\end{array}$ & $\begin{array}{c}\text { Classification de } \\
\text { D'Amico }\end{array}$ & PTNM & $\begin{array}{l}\text { ISUP post } \\
\text { opératoire }\end{array}$ \\
\hline 65 & 80 & T3aN0 M0 & G5 $(5+4)$ & haut risque & T3bN0 M0 & $\mathrm{G} 3(4+3)$ \\
\hline 58 & 14.97 & T3a N0 M0 & G5 $(4+5)$ & Haut risque & T3aN0 M0 & G5 $(5+4)$ \\
\hline 67 & 146 & T3b N0 M0 & $\mathrm{G} 4(4+4)$ & Haut risque & T3bN0 M0 & $\mathrm{G} 4(4+4)$ \\
\hline 70 & 52 & T3a N0 M0 & $\mathrm{G} 4(4+4)$ & Haut risque & T3aN0 M0 & $\mathrm{G} 4(4+4)$ \\
\hline 64 & 25 & T3b N0 M0 & $\mathrm{G} 3(4+3)$ & haut risque & T3bN0 M0 & $\mathrm{G} 4(4+4)$ \\
\hline 67 & 98.6 & T3b N0 M0 & $\mathrm{G} 3(4+3)$ & Haut risque & T3bN0 M0 & $\mathrm{G} 3(4+3)$ \\
\hline 73 & 16.6 & T3a N0 M0 & $\mathrm{G} 3(4+3)$ & Haut risque & T3aN0 M0 & $\mathrm{G} 3(4+3)$ \\
\hline 63 & 11.24 & T3a N0 M0 & $\mathrm{G} 3(4+3)$ & Haut risque & T3aN0 M0 & $\mathrm{G} 3(4+3)$ \\
\hline 63 & 42 & T2c N0 M0 & $\mathrm{G} 1(3+3)$ & Haut risque & T3a N0 M0 & $\mathrm{G} 3(4+4)$ \\
\hline 68 & 40 & T2b N0 M0 & $\mathrm{G} 1(3+3)$ & Haut risque & T3b N0 M0 & $\mathrm{G} 3(4+3)$ \\
\hline 59 & 20.8 & T2b N0 M0 & $\mathrm{G} 1(3+3)$ & Haut risque & T3b N0 M0 & $\mathrm{G} 3(4+3)$ \\
\hline 55 & 15 & T2b N0 M0 & $\mathrm{G} 1(3+3)$ & Risque intermédiaire & T3b N0 M0 & $\mathrm{G} 3(4+3)$ \\
\hline 57 & 12.23 & T3a N0 M0 & $\mathrm{G} 1(3+3)$ & Haut risque & T3a N0 M0 & $\mathrm{G} 3(4+3)$ \\
\hline 62 & 24.93 & T2b N0 M0 & $\mathrm{G} 1(3+3)$ & Haut risque & T2c N0 M0 & $\mathrm{G} 2(3+4)$ \\
\hline 54 & 17.33 & T1c N0 M0 & $\mathrm{G} 1(3+3)$ & Risque intermédiaire & T3b N0 M0 & $\mathrm{G} 2(3+4)$ \\
\hline 74 & 13.34 & T3b N0 M0 & $\mathrm{G} 1(3+3)$ & Haut risque & T3b N0 M0 & $\mathrm{G} 2(3+4)$ \\
\hline 70 & 36 & T2b N0 M0 & $\mathrm{G} 1(3+3)$ & Haut risque & T3a N0 M0 & $\mathrm{G} 1(3+3)$ \\
\hline 71 & 14.4 & T1C N0 M0 & $\mathrm{G} 1(3+3)$ & Risque intermédiaire & T3a N0 M0 & $\mathrm{G} 1(3+3)$ \\
\hline 57 & 12.5 & T2b N0 M0 & $\mathrm{G} 1(3+3)$ & Risque intermédiaire & T2c N0 M0 & $\mathrm{G} 1(3+3)$ \\
\hline 55 & 9 & T2c N0 M0 & $\mathrm{G} 1(3+3)$ & Haut risque & T3a N0 M0 & $\mathrm{G} 1(3+3)$ \\
\hline 66 & 8 & T2c N0 M0 & $\mathrm{G} 1(3+3)$ & haut risque & T3a N0 M0 & $\mathrm{G} 1(3+3)$ \\
\hline 58 & 8.5 & T3a N0 M0 & $\mathrm{G} 1(3+3)$ & Haut risque & T3a N0 M0 & $\mathrm{G} 1(3+3)$ \\
\hline 69 & 6.31 & T2c N0 M0 & G1 $(3+3)$ & Haut risque & T3b N0 M0 & $\mathrm{G} 1(3+3)$ \\
\hline
\end{tabular}


Treatment was open radical retropubic prostatectomy. After RP, the PSA level was undetectable $(<0.1 \mathrm{ng} / \mathrm{mL})$ in 4 patients over $4-6$ weeks. After recurrence all patients who were consenting had hormone therapy. Hormone therapy was medical with Goserelin and Triptorelin (7 patients) or surgical with bilateral testicular pulpectomy ( 1 patient). A response to hormone therapy was obtained in 05 patients and in 08 patients we noted progression.

The mean overall survival (OS) of the patients in the series was $28.1 \pm 34$ months. The overall survival of the series at 12 months; 24 months and 36 months was $69 \%$; $65 \%$ and $30 \%$ respectively (Figure 1 ). The mean biological recurrencefree survival in the series was $25.7 \pm 23$ months. Biological recurrence-free survival at 12 months; 24 months and 36 months was $80 \%$; 66\%; 60\% and $20 \%$ respectively (Figure 2).

\section{Discussion}

Positive surgical margins in men undergoing radical prostatectomy for prostate cancer are a common situation. According to Wright [9] PSM were reported in $21.2 \%$ of cases and were more common in pT3a than pT2 tumors and higher-grade tumors. We found a rate of $26.7 \%$ PSM. Data from the literature reported rates ranging from $16 \%$ to $47 \%$ [10] for series contemporary with ours.

In our context, the incidence of PCM may be related to the difficulty of radical prostatectomy in high-risk cancers but also to the locally advanced stage of the cancer in $91.3 \%$ of our patients $(n=21)$. Depending on the stage, there is an increase in PSM rate. For stages T1a, from $0 \%$ to $21 \%$, for stages T1b from $30 \%$ to $35 \%$ [11] For T2 stages, the figures range from $9 \%$ for T2a, 24\% for T2b and $40 \%$ for T2c in Rosen's series [12]. In the Mayo Clinic series [13], there were 30 and

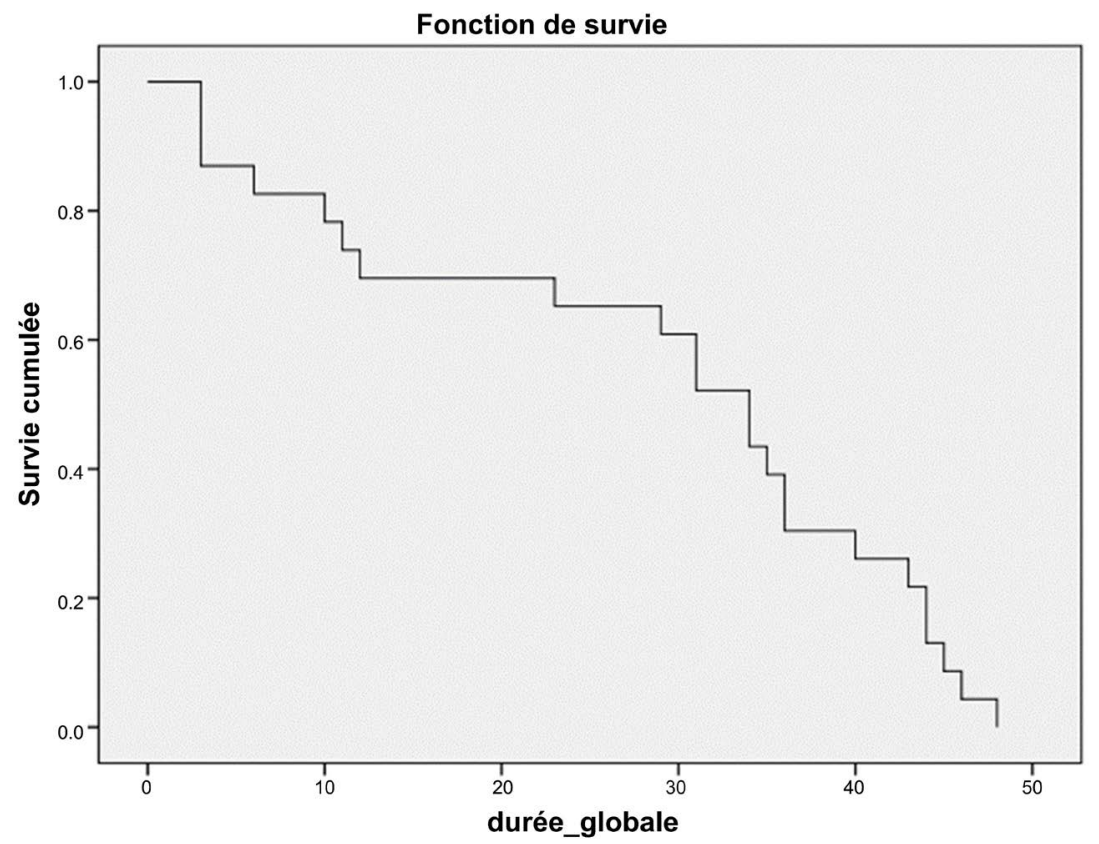

Figure 1. Overall survival curve (months). 


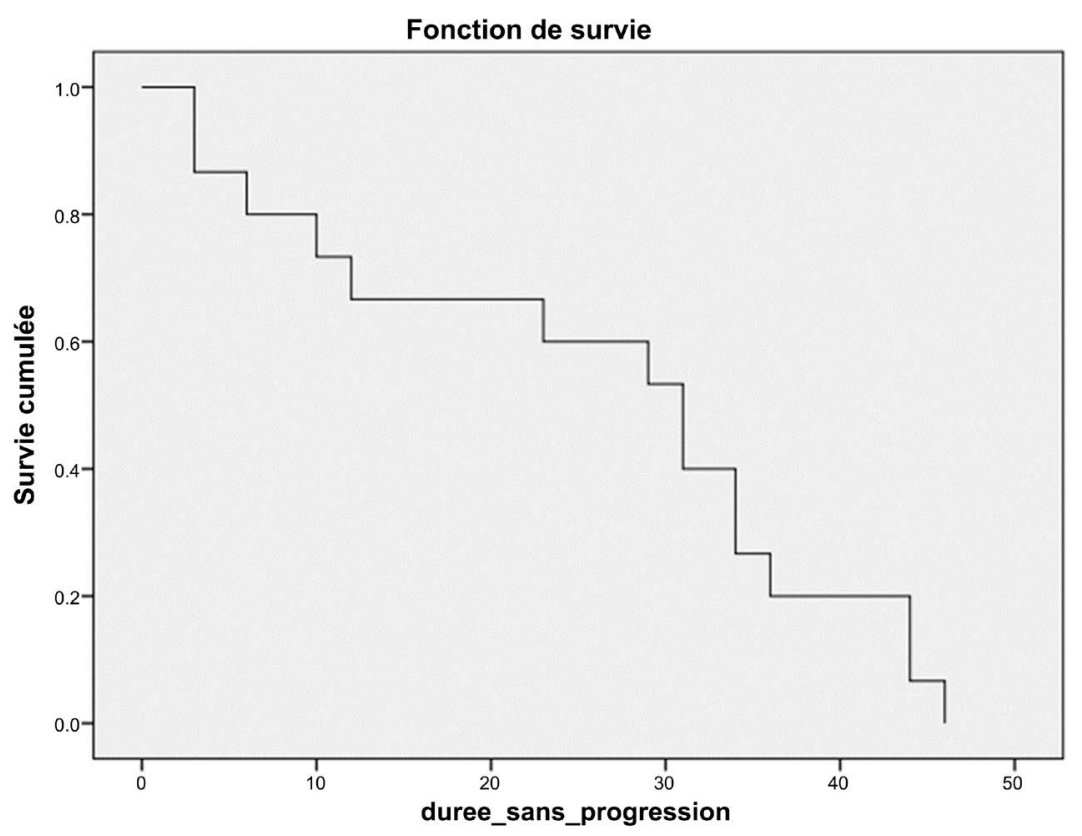

Figure 2. Biological recurrence-free survival curve (months).

$60 \%$ margins for $\mathrm{T} 1$ and $\mathrm{T} 2$. Moreover, a statistically significant interaction was found between surgical margin status and Gleason score 7 to $10(\mathrm{P}<0.008)$ and lymph node invasion $(\mathrm{P}<0.001)$.

The mean pre-therapeutic PSA level was $31.5 \mathrm{ng} / \mathrm{mL}$. The relationship between pre-treatment PSA and positive surgical margins is known. Indeed, Gomez and Shelfo have reported a correlation between PSA and PSM levels [14] [15].

Retropubic radical prostatectomy was performed in all our patients. Bladder neck preservation was not specified in the surgical report. According to Arroua [16] bladder neck preservation does not increase the risk of a PSM. In fact, more than $70 \%$ of their patients had early postoperative continence without increasing the number of positive surgical margins.

There is no consensus regarding the optimal management of PSM after total prostatectomy. Treatment options include surveillance, adjuvant radiotherapy and/or hormone therapy or salvage management at biological recurrence [17].

Immediate external irradiation after radical prostatectomy improves biochemical progression-free survival and local control in patients with positive surgical margins [6].

After recurrence all patients who were consenting received hormone therapy because hormone therapy was the main option to be offered to patients. We noted a response to hormone therapy in 5 patients and progression in 8 patients.

In our study then margins location were not specified. The effect on biochemical recurrence was influenced by the site of the surgical margin, with a posterolateral location having the most significant effect on prognosis [18]. Aydin et al. [19] have shown that the presence of surgical margins at the cervix increases the risk of biologic recurrence more than for any other location. 
According to Wright [10] PSM in men undergoing radical prostatectomy for prostate cancer are associated with an increased risk of biochemical recurrence.

The 7-year disease specific survival rates for those at highest risk for prostate cancer specific mortality (higher grade pT3a) were $97.6 \%$ for cases with negative surgical margins and $92.4 \%$ for those with positive surgical margins.

Overall survival and biological recurrence-free survival in our patients were low compared to data in the literature. This can be explained by the high rate of high risk of recurrence and locally advanced tumor in our series.

The limitation of this study is that it is a small series, we did not explore the factors that affect the prevalence of the PSM such as the surgical approach, the experience of the surgeon, and the tumor status and their localization in the prostate specimen are not specified.

\section{Conclusion}

Positive margins after total prostatectomy are a relatively common pathological situation in our daily practice of urologists dealing with prostate cancer. The status of the surgical margins as well as their situation in the event of positivity must be specified in the histology reports. Their presence should lead to a search for a biological recurrence in order to offer patients adequate treatment. Standard hormone therapy and radiotherapy are the therapeutic means available in our regions and they offer less survival to patients.

\section{Conflicts of Interest}

The authors declare no conflicts of interest regarding the publication of this paper.

\section{References}

[1] Gomez, S.L., Le, G.M., Clarke, C.A., Glaser, S.L., France, A.M. and West, D.W. (2003) Cancer Incidence Patterns in Koreans in the US and in Kangwha, South Korea. Cancer Causes \& Control, 14, 167-174. https://goo.gl/pP6VR2 https://doi.org/10.1023/A:1023046121214

[2] Diao, B., Fall, B., Fall, P.A., Ze Ondo, C., Sow, Y., Ndoye, A.K., et al. (2008) Prise en charge chirurgicale du cancer de la prostate à Dakar: analyse d'une série de 96 cas. Dakar Medical, 53, 124-129.

[3] Ndiaye, M., Sow, O., Sine, B., Gaye, O., Sarr, A., Ndiath, A., et al. (2020) Metastatic Prostate Cancer under Androgen Deprivation Therapy: Factors Influencing Castration Resistance. Open Journal of Urology, 10, 225-232. https://doi.org/10.4236/oju.2020.107026

[4] Millin, T. (1948) Retropubic Prostatectomy. The Journal of Urology, 59, 267-274. https://doi.org/10.1016/S0022-5347(17)69374-1

[5] Yossepowitch, O., Briganti, A., Eastham, J.A., et al. (2014) Positive Surgical Margins after Radical Prostatectomy: A Systematic Review and Contemporary Update. $E u$ ropean Urology, 65, 303-313. https://doi.org/10.1016/j.eururo.2013.07.039

[6] Bolla, M., van Poppel, H., Tombal, B., et al. (2012) Postoperative Radiotherapy after Radical Prostatectomy for High-Risk Prostate Cancer: Long-Term Results of a 
Randomized Controlled Trial (EORTC trial 22911). Lancet, 380, 2018-2027. https://doi.org/10.1016/S0140-6736(12)61253-7

[7] Stamey, T.A., Villers, A.A., McNeal, J.E., et al. (1990) Positive Surgical Margins at Radical Prostatectomy: Importance of the Apical Dissection. The Journal of Urology, 143, 1166-1172. https://doi.org/10.1016/S0022-5347(17)40216-3

[8] Epstein, J.I. (1996) Incidence and Significance of Positive Margins in Radical Prostatectomy Specimens. Urologic Clinics of North America, 23, 651-663. https://doi.org/10.1016/S0094-0143(05)70343-8

[9] Watson, R.B., Civantos, F. and Soloway, M.S. (1996) Positive Surgical Margins with Radical Prostatectomy: Detailed Pathological Analysis and Prognosis. Urology, 48, 80-90. https://doi.org/10.1016/S0090-4295(96)00092-1

[10] Wright, J.L., Dalkin, B.L., True, L.D., Ellis, W.J., Stanford, J.L., Lange, P.H., Lin, D.W. (2010). Positive Surgical Margins at Radical Prostatectomy Predict Prostate Cancer Specific Mortality. The Journal of Urology, 183, 2213-2218. https://doi.org/10.1016/j.juro.2010.02.017

[11] Cheng, W.S., Frydenberg, M., Bergstralh, E.J., Larson-Keller, J.J. and Zincke, H. (1993) Radical Prostatectomy for Pathologic Stage C Prostate Cancer: Influence of Pathologic Variables and Adjuvant Treatment on Disease Outcome. Urology, 42, 283-291. https://doi.org/10.1016/0090-4295(93)90617-J

[12] Rosen, M.A., Goldstone, L., Lapin, S., Wheeler, T. and Scardino, P.T. (1992) Frequency and Location of Extracapsular Extension and Positive Surgical Margins in Radical Prostatectomy Specimens. The Journal of Urology, 148, 331-337. https://doi.org/10.1016/S0022-5347(17)36587-4

[13] Karakiewicz, P.I., Eastham, J.A., Graefen, M., Cagiannos, I., et al. (2005) Prognostic Impact of Positive Surgical Margins in Surgically Treated Prostate Cancer: Multi-Institutional Assessment of 5831 Patients. Urology, 66, 1245-1250. https://doi.org/10.1016/j.urology.2005.06.108

[14] Gomez, C.A., Soloway, M.S., Civantos, F., et al. (1993) Bladder Neck Preservation and Its Impact on Positive Surgical Margins during Radical Prostatectomy. Urology, 42, 689-693. https://doi.org/10.1016/0090-4295(93)90534-H

[15] Shelfo, S.W., Obek, C. and Soloway, M.S. (1998) Update on Bladder Neck Preservation during Radical Retropubic Prostatectomy: Impact on Pathologic Outcome, Anastomotic Strictures, and Continence. Urology, 51, 73-78. https://doi.org/10.1016/S0090-4295(97)00463-9

[16] Arroua, F., Toledano, H., Gaillet, S., Saidi, A., Breton, X., Delaporte, V., et al. (2008) Radical Prostatectomy with Bladder Neck Preservation: Surgical Margins and Urinary Continence. Progrès en Urologie, 18, 304-310.

https://doi.org/10.1016/j.purol.2008.03.023

[17] Staerman, F., Soulie, M., Tostain, J., et al. (2006) Prise en charge des marges positives après prostatectomie totale pour cancer localisé de la prostate. Progrès en Urologie, 16, 286-291.

[18] Eastham, J.A., Kuroiwa, K., Ohori, M., Serio, A.M., Gorbonos, A., Maru, N., et al. (2007) Prognostic significance of location of positive margins in radical prostatectomy specimens. Urology, 70, 965-969.

https://doi.org/10.1016/j.urology.2007.08.040

[19] Aydin, H., Tsuzuki, T., Hernandez, D., Walsh, P.C., Partin, A.W. and Epstein, J.I. (2004) Positive Proximal (Bladder Neck) Margin at Radical Prostatectomy Confers Greater Risk of Biochemical Progression. Urology, 64, 551-555.

https://doi.org/10.1016/j.urology.2004.04.003 